\title{
Nonlinear Model Selection for Fruit and Kernel Development as a Function of Heat in Pistachio
}

\author{
Lu Zhang \\ Department of Horticulture and Landscape Architecture, Oklahoma State \\ University, Stillwater, OK 74078
}

Emilio Laca

Department of Plant Sciences, University of California Davis, One Shields Avenue, Davis, CA 95616

Cara J. Allan

Vegetable Seeds Americas, Syngenta US, Woodland, CA 95695

Narges M. Mahvelati

Wonderful Orchards, Lost Hills, CA 93249

\section{Louise Ferguson}

Department of Plant Sciences, University of California Davis, One Shields Avenue, Davis, CA 95616

Additional index words. embryo, Gompertz model, nut growth, Pistacia vera

\begin{abstract}
Knowing a tree crop's seasonal growth and development as a function of heat accumulation can facilitate scheduling of irrigation, pesticide applications, and harvest. Our objective was to compare the goodness of fit of applied models and determine which provides the best description of pistachio nut growth as a function of thermal unit accumulation. Three fruit growth traits of pistachio - pericarp (hull) + endocarp (shell) size, endocarp thickening and hardening, and embryo (kernel) size - exhibited clear nonlinear dependence on heat accumulation. We tested three nonlinear models-Michaelis-Menten, three-parameter logistic, and Gompertz- fitted to fruit development data to create a tool to forecast pest susceptibility and harvest timing. Observation of development began at full bloom and ended at harvest. Data were collected from six pistachio cultivars in one experimental and eight commercial orchards over 3 years. Analyses of residual distribution, parameter standard errors, coefficient of determination $\left(R^{2}\right)$ and the Akaike information criterion (AIC) all demonstrated the Gompertz function was the best model. Cultivars differed significantly in all the three parameters (Asym, $b$, and $c$ ) for all three traits with the Gompertz model, demonstrating the Gompertz model can adjust to incorporate cultivar differences. The growth curve of the three traits together provided integrated information on nut biomass accumulation that facilitates predicting the critical timing for multiple orchard management practices.
\end{abstract}

The rate of vegetative and reproductive growth in plants is dependent on temperature. Annual temperature accumulations are particularly important in deciduous nut trees (e.g., pistachio, pecan, walnut, hazelnut), which have specific winter dormancy chill accumulation requirements, and spring-through-harvest heat accumulation requirements for bloom, nut growth, and ripening (Benmoussa et al., 2017; Costa et al., 2021; Egea et al., 2003). A recent carbohydrate-temperature model of deciduous trees demonstrated warm spring temperatures promote starch accumulation over soluble sugars, precipitating bloom (Sperling et al., 2019). Warm temperatures accelerate the rate of cell elongation and metabolic activities (Olsen, 2010). When the development of plant organs is related to temperature, the resulting relationship follows a growth curve that includes critical low, optimal, and critical high temperatures (Chuine and Régnière, 2017). Heat units are calculated using these threshold temperatures is $7.5^{\circ} \mathrm{C}$, the optimum temperature is $26^{\circ} \mathrm{C}$, and the critical high temperature is $38.5^{\circ} \mathrm{C}$ (Marra et al., 2002). Among grape cultivars, the lowest critical temperatures range from 8.7 to $10.7^{\circ} \mathrm{C}$ and the highest vary from 11.8 to $12.8^{\circ} \mathrm{C}$ (Zapata et al., 2015). In our research, the value of $7^{\circ} \mathrm{C}$ was set as the minimum requirement for pistachio nut growth.

The concept of plant growth and development being a function of temperature was developed during the early 18 th century (Wilson and Barnett, 1983). New Zealand 'Royal Gala' apples were reported as requiring heat units ranging from 1316 to 1523 GDDs from pollination through harvest using $5^{\circ} \mathrm{C}$ as base temperature (Stanley et al., 2015). Highbush blueberry needs $\approx 1200$ GDDs for berry maturity using the lower threshold temperature of $7^{\circ} \mathrm{C}$ (Godoy et al., 2008). Heat requirements vary among varieties. A wide range of fruit development periods was reported for peaches (Marra et al., 2002). Recent testing of multiple models on multiple tree fruit crops concluded using thermal time to predict plant growth is more precise than calendar days (Darbyshire et al., 2014).

Fruit, or nut, growth can be calculated from bloom through maturation in deciduous trees (Stajnko et al., 2013; Zavalloni et al., 2006) using specific reproductive organs as biomarkers. Female flowers usually have three functional structures: stigma, style, and ovary. The ovary wall has three layers: exocarp, mesocarp, and endocarp. In pistachio, the exocarp and mesocarp form the hull and the endocarp, the shell. Within the ovule, fertilization occurs, producing a zygote (Goldberg et al., 1994). Zygotes become the embryo (kernel) containing the cotyledons and the axis. Cotyledons are the edible nut meat. Pistachio nut growth has three stages: 1) hull and shell expansion that produces the final in-shell nut size; 2) thickening and hardening of the pistachio shell, a lignification process; 3 ) and embryo (kernel) growth that splits the shell mechanically, producing the commercially desired "in-shell split" pistachio (Goldhamer and Beede, 2004).

Models predicting plant phenological stages are widely used in crop production (Chuine and Régnière, 2017). Modeling the progress of embryonic organ development makes the prediction of nut growth possible and facilitates agricultural activities (Prusinkiewicz, 2004). It is crucial for pistachio growers to know when specific growth stages occur to maximize the efficiency of irrigation, pest management, and optimum harvest time. It is well established that pistachio water requirements change over the growing season. Hull and shell expansion (stage 1) require full replacement of evapotranspiration by irrigation for maximum growth, but shell hardening (stage 2) requires less water (Ferguson et al., 2005). It has been demonstrated that if there is a $50 \%$ reduction in irrigation during stage 2 , but before the initiation of embryo expansion, nut quality is unaffected (Goldhamer and Beede, 2004), allowing water savings. Management of mirid (Calocoris norvegicus) and lygus (Lygus hesperus), insects that can deform only the young soft-shell nuts, would be greatly facilitated by the ability to 
Table 1. Description of collection sites and cultivars including sampling year, locations, elevation, soil type, and rootstocks of pistachio orchards used in this study.

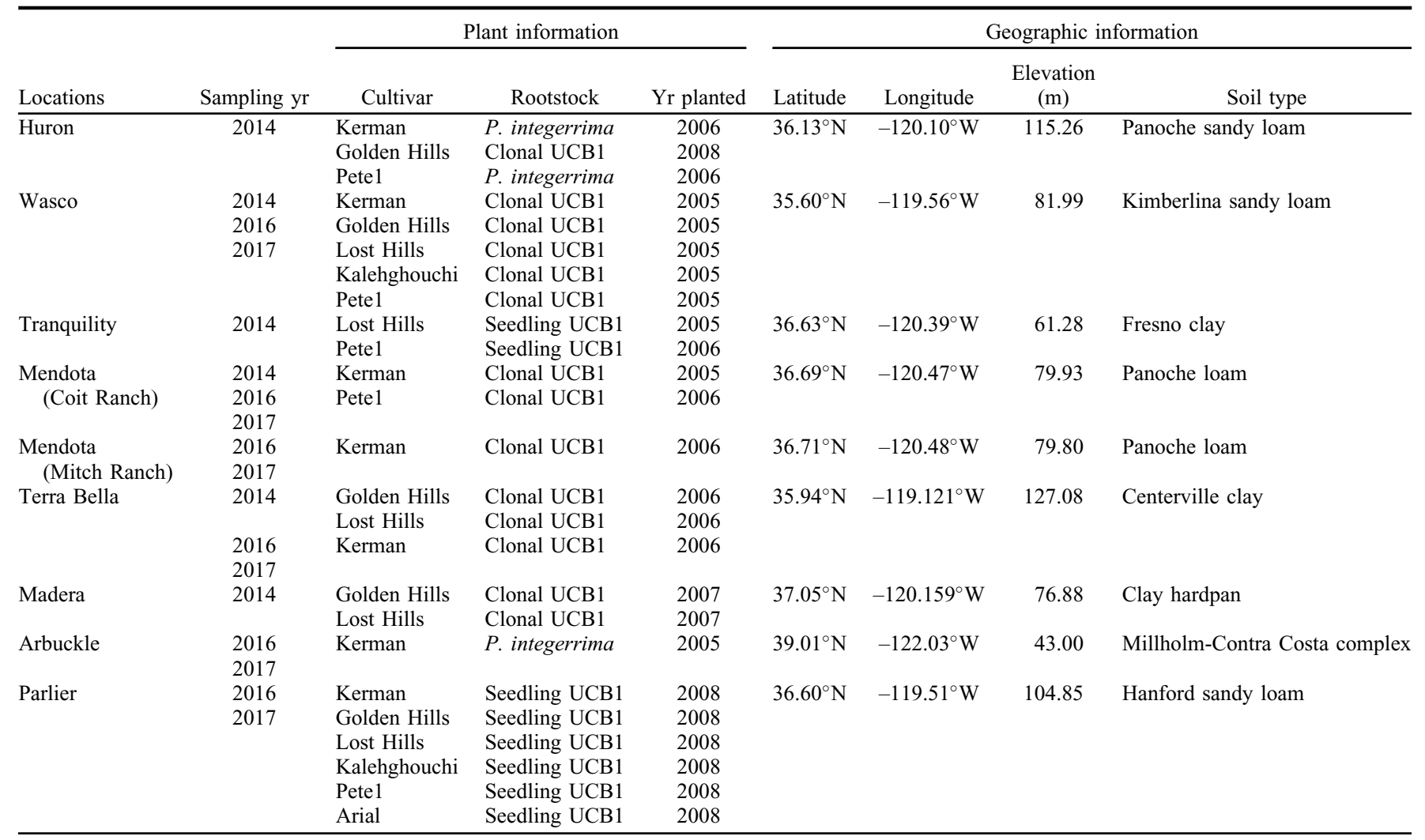

predict when the shells become sufficiently hard to prevent damage (Bentley et al., 2016). A poorly timed harvest can decrease yield and quality through shell staining by senescing hulls, and increase the probability of navel orangeworm (Amyelois transitella) infestation (Haviland et al., 2016). The ability to predict each stage of nut growth will aid in orchard operation scheduling and efficiency, and will increase net return.

The objective of our work was to develop a model that best describes the three growth stages of pistachio fruit (hull + shell growth, shell hardening, and kernel development) as a function of heat unit accumulation. Nuts of six

Received for publication 22 Jan. 2021. Accepted for publication 19 Mar. 2021.

Published online 2 June 2021.

This work was supported by the California Pistachio Research Board.

We thank our cooperating growers and managers: Alan Scroggs, Bill Seaman, Charlie Rose, Chris Couture, Dave Peterson, Gary Robinson, Gary Weinberger, Ali Orandi, Hamid Orandi, Jeff Gibbons, Jeff Schmeidrer, Jonathan Battig, Mitchell Coit, Setton Farms, and Vahid Salehi. We thank Craig Kallsen, University of California Cooperative Extension Kern County Farm Advisor and Themis Michailides, Department of Plant Pathology, University of California Davis and Kearney Agricultural Research and Extension Center, University of California Agricultural and Natural Resources for providing the experimental orchards.

L.Z. is the corresponding author. E-mail:

luzhang@okstate.edu.

This is an open access article distributed under the CC BY-NC-ND license (https://creativecommons. org/licenses/by-nc-nd/4.0/). pistachio cultivars planted in nine different California microclimates were collected from fruit set through harvest for three growing seasons. Four nonlinear models - asymptotic regression, Michaelis-Menten, three-parameter logistic, and Gompertz - were compared.

\section{Material and Methods}

Location and cultivar. The study was carried out during 2014, 2016, and 2017 in one experimental orchard (Parlier, Kearney Agricultural Research and Extension Center, University of California) and eight commercial orchards located near the cities Arbuckle, Huron, Madera, Mendota, Tranquility, and Wasco, CA. Six Pistacia vera cultivars - Kerman, Golden Hills, Lost Hills, Kaleghouchi, Pete1, and Aria - were used. Details of the geography (latitude, longitude, elevation, and soil type) and plant information (rootstock and year planted) of each location and cultivar are listed in Table 1.

Measurements. Accumulation of heat units began when a visual estimate indicated $50 \%$ full bloom on female trees. Nuts were collected weekly from the initiation of fruit growth through harvest. Three trees of each cultivar with similar tree vigor and canopy size were selected for sampling at each location. One randomly selected cluster of nuts in each side (north, south, east, and west) was collected and 10 terminal nuts of each of the four clusters were picked for further measurement. Length, width, and height of the 10 nuts were measured with a Willrich Precision 16 ER Mahr Federal digital caliper (Mahr Inc., Providence, RI) with a USB data output and
Marcom Interface Software (16 EXU, 4102357) to an Excel spreadsheet. Volume was calculated using the equation for the volume of an ellipsoid Eq. [2] with the observed length, width, and height measurements:

Volume $=\frac{4}{3 \pi}\left(\frac{\text { Length }}{2}\right)\left(\frac{\text { Width }}{2}\right)\left(\frac{\text { Height }}{2}\right)$.

Shell hardness was tested using a force gauge (ZTS Series; Imada Co., Ltd., Northbrook, IL) with a 3-mm-diameter probe needle. The nuts were cut into longitudinal sections and the embryo lengths were measured using a digital caliper. Data for each nut characteristic were averaged for each orchard and date (Table 1).

Temperature and heat unit. Temperature at each location was recorded hourly using data loggers (Onset HOBO ${ }^{\circledR}$ U23-001 Pro v2 Temperature/RH Data Loggers; Onset, Bourne, MA) housed in ultraviolet protection shields (Onset HOBO $^{\circledR}$ Solar Radiation Shield) facing north and south. The thermal units (tu) were determined by taking a daily average and subtracting the base temperature threshold as shown in Eq. [3]:

Thermal units $=\left(\frac{\text { Sum of temperature readings }}{\text { No. of readings used }}\right)-7^{\circ} \mathrm{C}$

Models. We fit and compared four models to each nut variable: asymptotic regression with offset, Michaelis-Menten with offset, three-parameter logistic, and Gompertz. Models were coded in R (Pinheiro et al., 2021) with the functions SSasympoff, SSlogis, and SSgompertz in the stats package and a custom 
Michaelis-Menten with offset function. The asymptotic regression model was

$y(x)=\operatorname{Asym}\left\{1-\exp \left[-\exp (\operatorname{Irc}) \times\left(x-c_{0}\right)\right]\right\}$,

where $x$ is thermal units, Asym is the asymptote, Irc is a parameter that modulates the change in slope, and $c_{0}$ is the offset or value of $x$ when $y=0$. The Michaelis-Menten with offset was

$$
y(x)=\frac{V_{m}\left(x-c_{0}\right)}{K+x-c_{0}},
$$

where $V_{m}$ is the asymptote, $c_{0}$ is the offset, and $K$ is the distance between the value of $x$ where $y$ is half of $V_{m}$ and the offset. The three-parameter logistic model was

$$
y(x)=\frac{\text { Asym }}{1+\exp \left(\frac{\text { xmid }-x}{\text { scal }}\right)},
$$

where Asym represents the asymptote approached as the nut grows, xmid is the total thermal units (measured in degree-days) needed to reach half the asymptote, and scal modulates the steepness of the curve as it increases from zero toward the asymptote. The Gompertz model was

$$
y(x)=\operatorname{Asym} \times \exp \left(-b \times c^{x}\right),
$$

where Asym is the asymptote, $b$ translates the curve in the $x$-axis, and $c$ determines the growth rate.

Models were fitted to the data using the nlme package (Pinheiro et al., 2021). Orchard identity and year were used as random effects for all parameters, and cultivar was specified as a fixed effect for all parameters. Models were simplified by removing nonsignificant effects. Residuals were inspected to determine homogeneity of variance and independence (Fig. 1). Deviations from assumptions were corrected by modeling variances and covariances using the "weights" and "corr" arguments of the nlme function. Thermal units necessary to achieve $90 \%$ of the maximum values of nut volume and embryo length and their confidence intervals were calculated using the Delta method of the car package (Fox and Weisberg, 2019). For all models, the coefficient of determination values $R^{2}$ and the AIC were evaluated as a basis to determine the better model (Nakagawa and Schielzeth, 2013).

\section{Results}

Model comparisons. The scatterplots of the standardized residuals (Fig. 1) show the differences between the observed and the predicted values of traits among the four models. The residuals provided by asymptotic regression and Michaelis-Menten models showed an asymmetric scatter at the beginning of the season when fruit volume was less than $2000 \mathrm{~mm}^{3}$, shell hardness was less than $10 \mathrm{lb} / 3 \mathrm{~mm}^{2}$, and embryo length was less than $10 \mathrm{~mm}$ (Fig. $2 \mathrm{~B}$ and C). The residuals were distributed more evenly and randomly around the zero line in the logistic and Gompertz models, which means the two
A

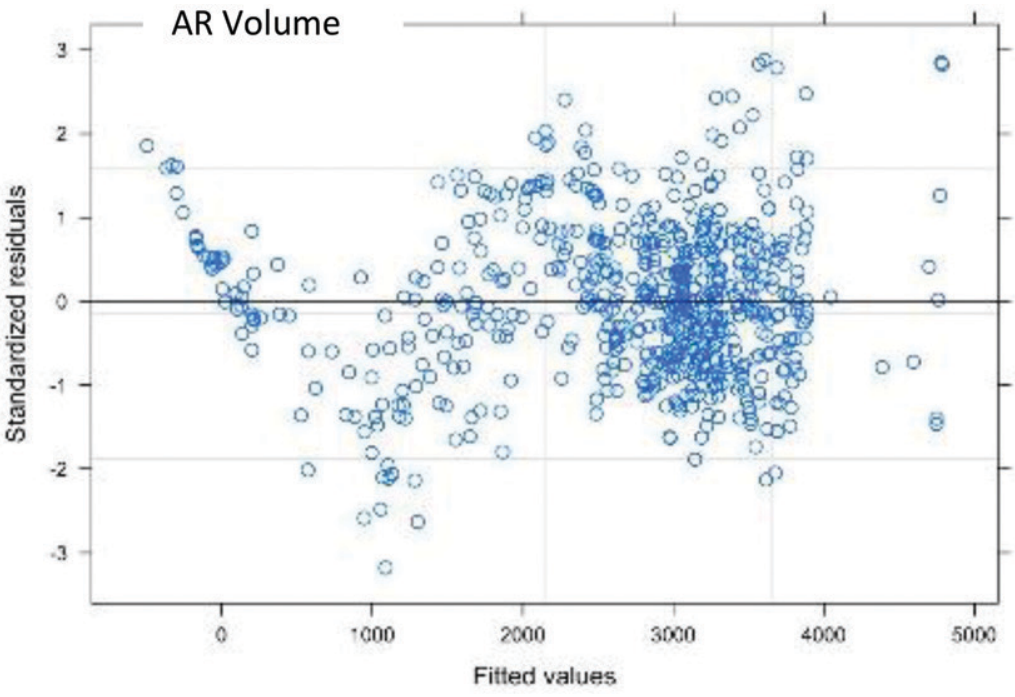

B

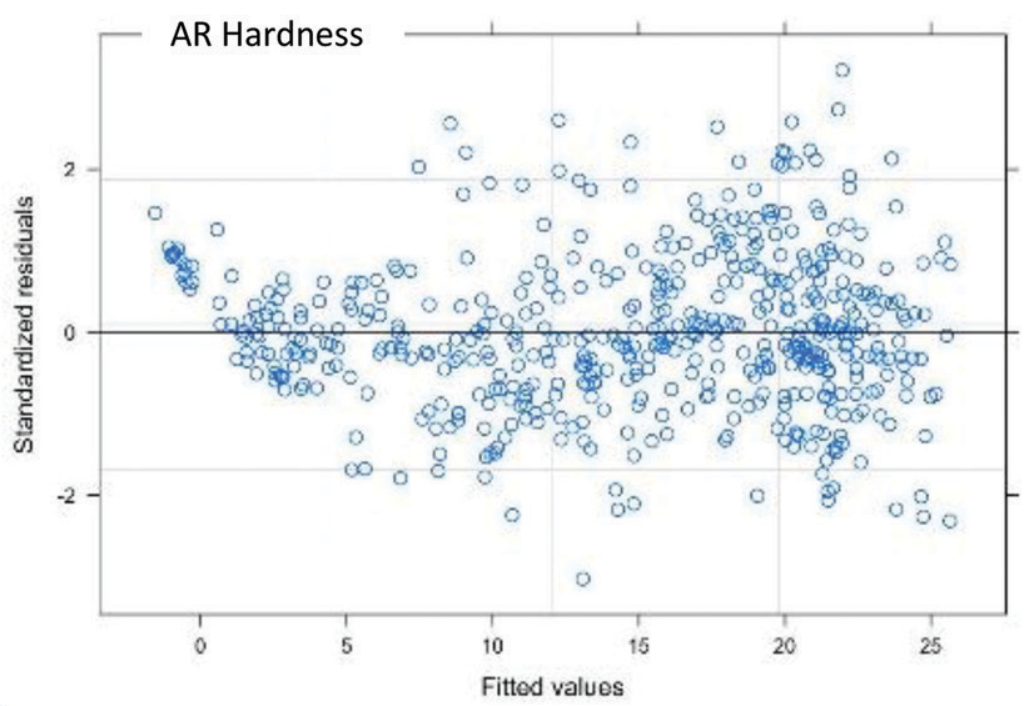

C

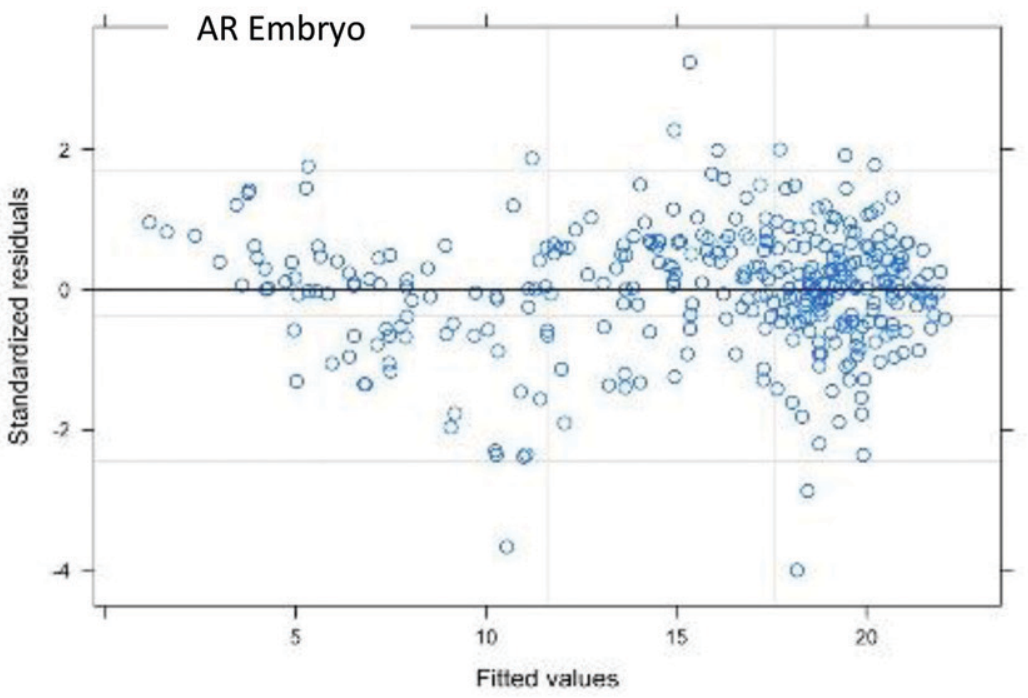

Fig. 1. Residuals (Observed - Predicted) for the asymptotic regression (AR), Michaelis-Menten (MM), three-parameter logistic (Log), and Gompertz (Gom) models fitted to pistachio nut growth data of $(\mathbf{A}, \mathbf{D}, \mathbf{G}, \mathbf{J})$ volume, $(\mathbf{B}, \mathbf{E}, \mathbf{H}, \mathbf{K})$ shell hardness, and $(\mathbf{C}, \mathbf{F}, \mathbf{I}, \mathbf{L})$ embryo length collected in 2014, 2016 and 2017. 


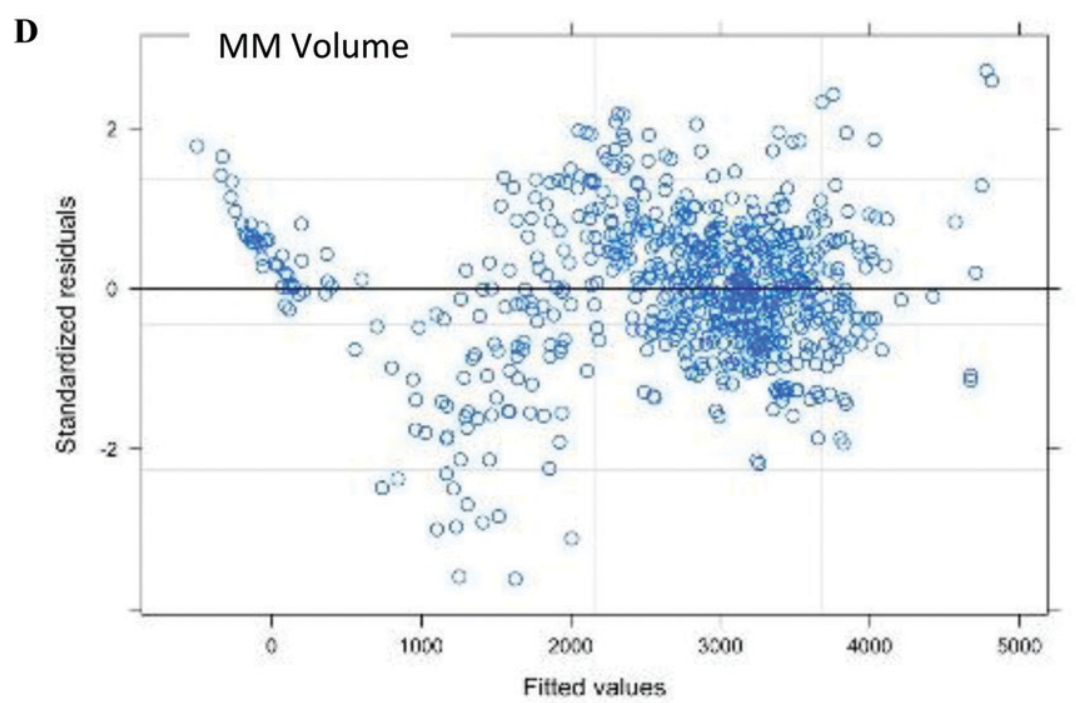

$\mathbf{E}$

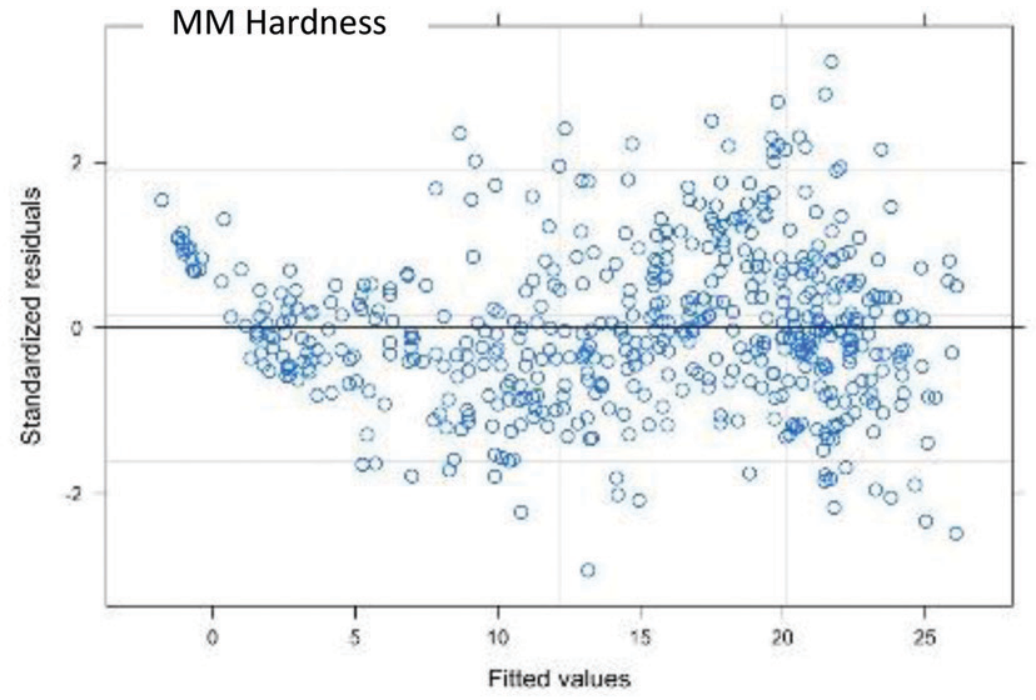

F

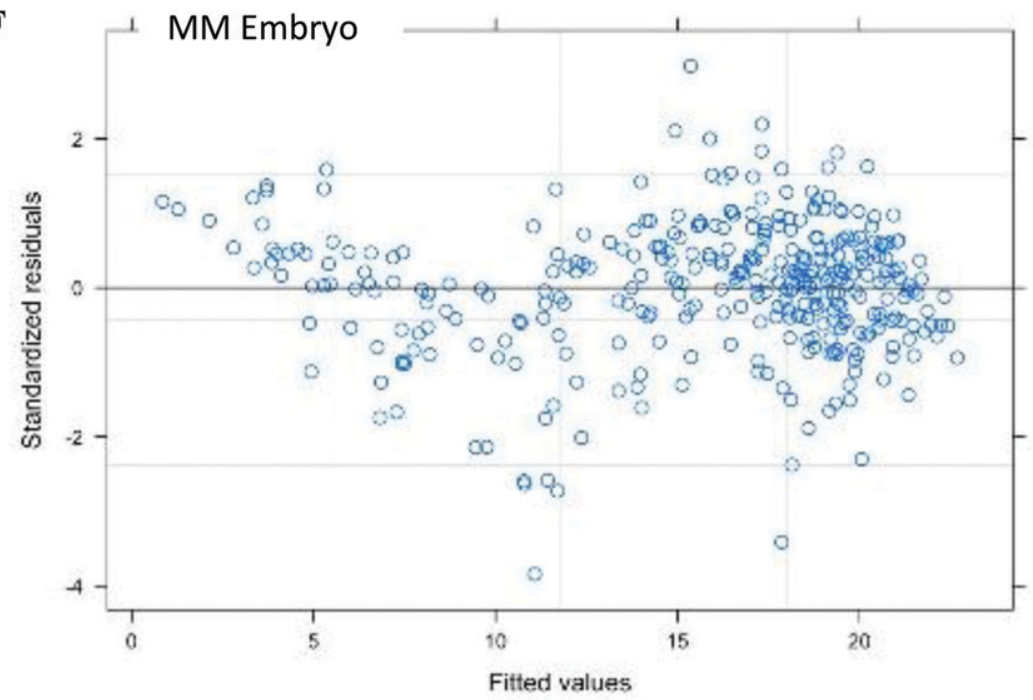

Fig. 1. (Continued) models are more suitable for fitting pistachio nut growth.

A separate analysis of variance was done on each parameter to evaluate the impact of the fixed effect (cultivar) on nut growth curves fitted by the four different types of models (Table 2$)$. The parameters $(P>0.05)$ mentioned earlier needed to be removed or adjusted because the fixed effect (cultivar) had no significant effect on the model response. In the asymptotic regression, logistic, and Michaelis-Menten models, the effect of cultivar was not significant $(P>0.05)$ for two parameters of nut volume: the Irc and $c_{0}$ in the asymptotic regression model, $K$ and $c_{0}$ in Michaelis-Menten, and xmid and scal in the logistic model. When modeling nut hardness, one parameter was invalid because the fixed effect had no impact on it: $c_{0}$ in the asymptotic regression and Michaelis-Menten models, and xmid in the logistic model.

For all the models, $R^{2}$ (Table 3 ) was more than 0.86 , which indicates how much of the variance is explained by the model. The AIC demonstrated that embryo length is better suited to the four models than the other two growth parameters. The Gompertz model had a high $R^{2}$ value of 0.95 in fitting embryo length. Both the $R^{2}$ values and the AIC indicated the Gompertz model was the best model for all variables.

Model-based nut growth description. The ability to predict growth initiation differed among models, particularly at the early stages of fruit development (Fig. 2A). All cultivars exhibited rapid postbloom growth. The growth curves of most of the cultivars approached the horizontal asymptote (maximum volume) between 500 and 1000 tu, depending on the model (Fig. 2A). The thermal units necessary to reach $90 \%$ of the asymptote (Fig. 3) was greatest for the Michaelis-Menten model in all cases, and least for the logistic and Gompertz models. The logistic model predicted the earliest development for all nut characteristics. Compared with the logistic and Gompertz models, the asymptotic regression and MichaelisMenten models reached $90 \%$ of the asymptote much later, requiring an estimated 1765 degree-days (averaged over cultivars) to reach $90 \%$ of the final nut volume, and 1674 degree-days to reach $90 \%$ of the embryo length. Final nut volumes differed significantly among cultivars. 'Pete 1' had the largest volume at $3742 \mathrm{~mm}^{3}$ whereas 'Aria' had the smallest volume at $2486 \mathrm{~mm}^{3}(90 \%$ of the asymptotes). The three commercial cultivars Kerman, Lost Hills, and Golden Hills were of medium size, between 3036 and $3132 \mathrm{~mm}^{3}$ (90\% of the asymptotes).

Unlike nut volume, which peaked early during the season, the curve of shell lignification, increased through the season to harvest (Fig. 2B). The asymptotic model with an offset showed that the data did not cover a range as close to the asymptote as for other characteristics. The thermal units necessary to reach $85 \%$ or $90 \%$ of the maximum hardness may be much greater than the range measured. At harvest, shell lignification of all cultivars was 
G

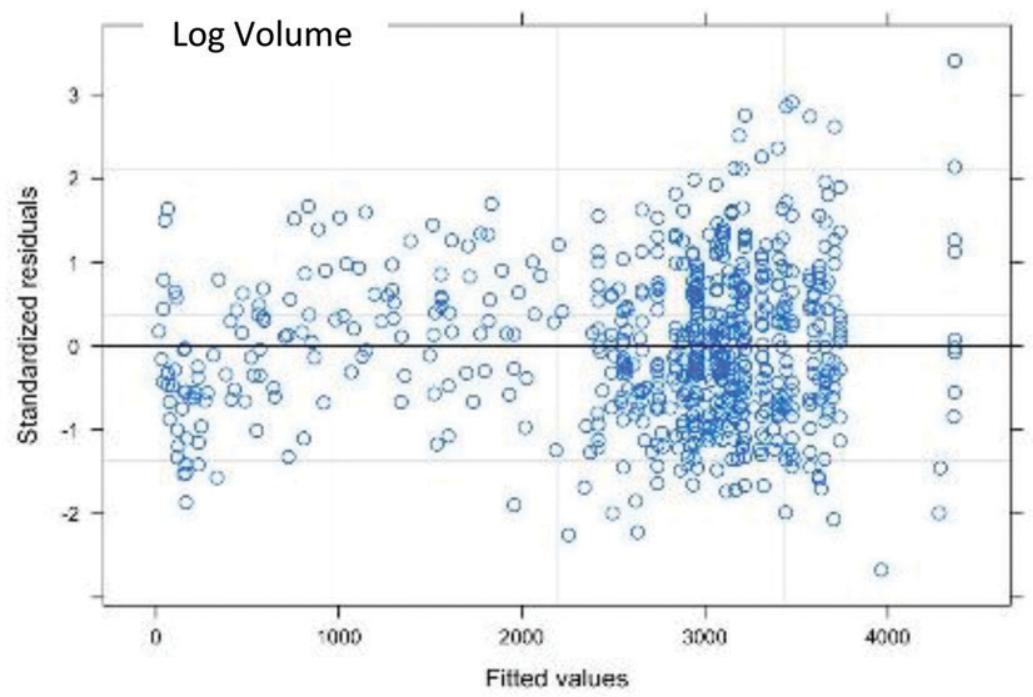

H

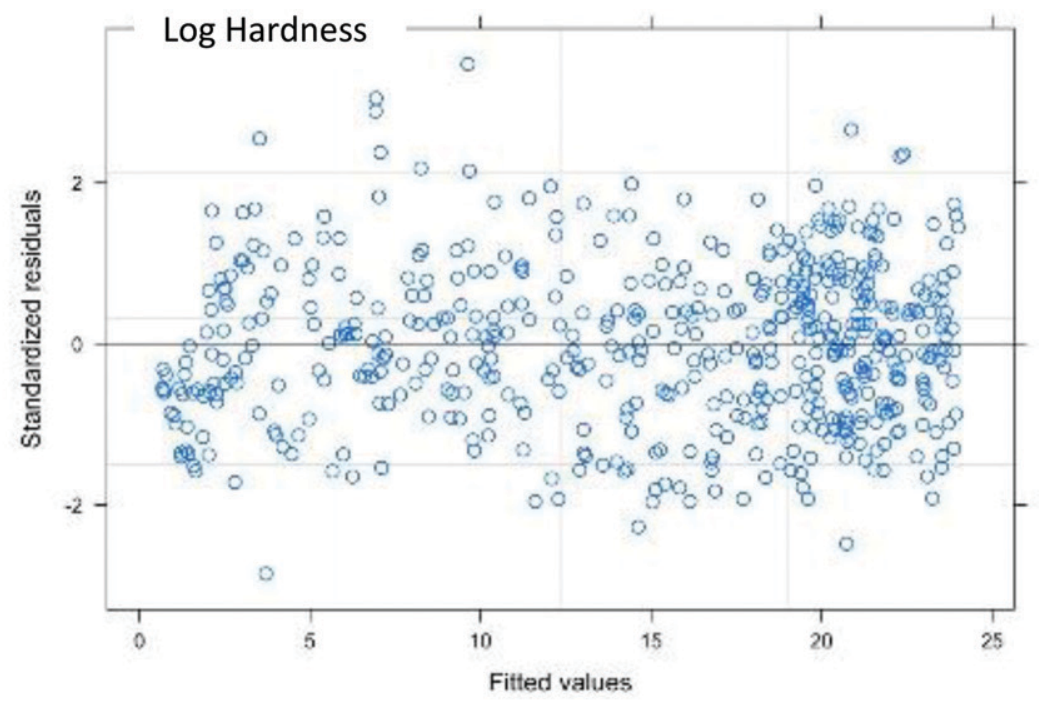

I

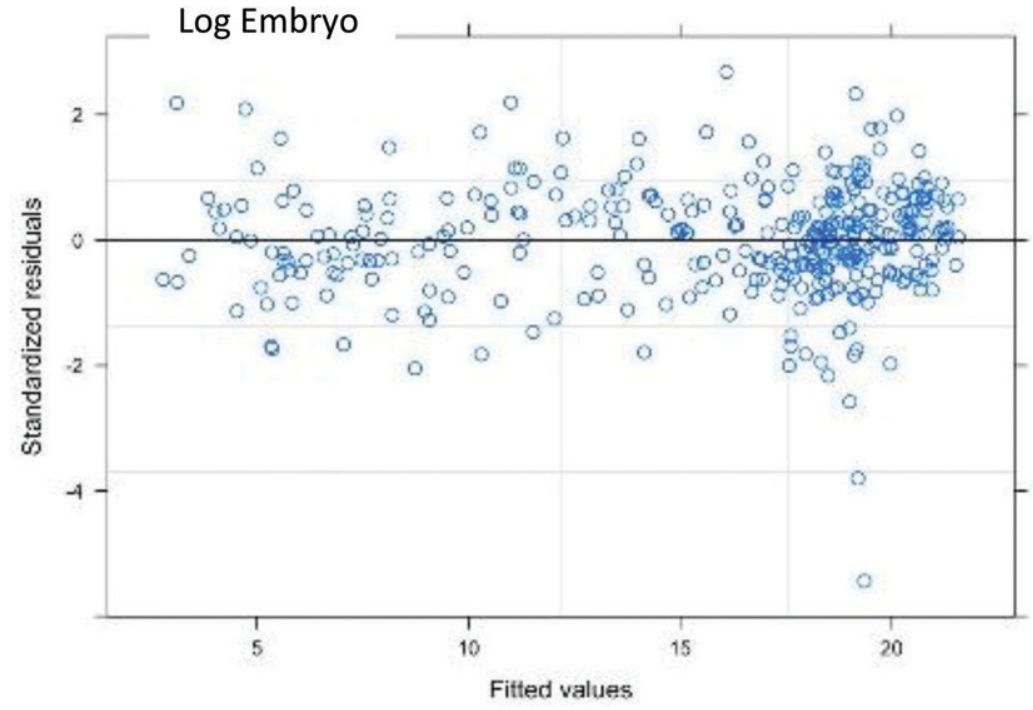

Fig. 1. (Continued) about equal except for 'Kerman', which was 2 to $3 \mathrm{lb} / 3 \mathrm{~mm}^{2}$ greater than that of the other cultivars. Maximum values $(90 \%$ of the asymptotes) of shell hardness estimated by the Gompertz model for 'Aria', 'Golden Hills', 'Kaleghouchi', 'Kerman', 'Lost Hills', and 'Pete 1' were 21.5, 21.5, 19.9, 23.9, 21.6, and $22.1 \mathrm{lb} / 3 \mathrm{~mm}^{2}$.

The embryo started growing at $\approx 750$ tu and reached $90 \%$ of maximum size at $\approx 1760$ tu on average, varying among the cultivars (Fig. 2C). 'Golden Hills' and 'Lost Hills' reached the maximum value earliest when fitted by the logistic and Gompertz models. The predicted maximum asymptotic values of embryo length were a bit greater $(2-3 \mathrm{~mm})$ for 'Golden Hills' and 'Lost Hills' than for 'Kaleghouchi' and 'Pete 1'. The latter had embryos 2 to $3 \mathrm{~mm}$ larger than those of 'Aria' and 'Kerman'. 'Pete 1' had the largest shell, but its kernel was relatively smaller. This considered, and the observation that it barely reached maximum size at harvest, supports the commercial growers' observations that 'Pete 1' consistently has an extremely high percentage of partially filled nuts. It appears 'Pete 1' requires very high heat units to fill its larger shell successfully.

\section{Discussion}

The objective of our research was to develop a model that could predict pistachio nut growth stages to facilitate production decisions - specifically, when $90 \%$ (90\% confidence intervals) of the maximum in-shell nut volume, kernel length, and shell hardness were achieved. The underlying logic that phenology of nut growth modeled as a function of degree-days accounts for differences in development rate resulting from temperature and is more accurate than basing production decisions on the calendar, Julian, or days after full bloom. Different types of nonlinear models were compared to select the one that provided the most accurate predictions.

Fitting nonlinear models to data is being done increasingly in plant physiology; the recent multiple methods of calculating dormant chill accumulation models are an example. Less attention has focused on modeling fruit or nut growth as a function of heat unit in deciduous trees (Chuine et al., 1999; Pope et al., 2014). Nonlinear growth models are flexible in the variations of growth rate, and many existing nonlinear models have been used in plant physiological research, such as Michaelis-Menten, Gompertz, and logistic models (Godoy et al., 2008; Tudela and Santibáñez, 2016). Compared with linear models, which explain growth curves after data conversion, the benefit of nonlinear modeling is that the estimated parameters can be explained clearly. For example, the asymptote in the Michaelis-Menten model refers to the maximum reaction rate in enzyme catalysis. The essence of model selection is to fit the data to a certain function and related parameters. Least-squares regression techniques have been used widely in nonlinear model regression analysis by minimizing the sum of 
$\mathbf{J}$

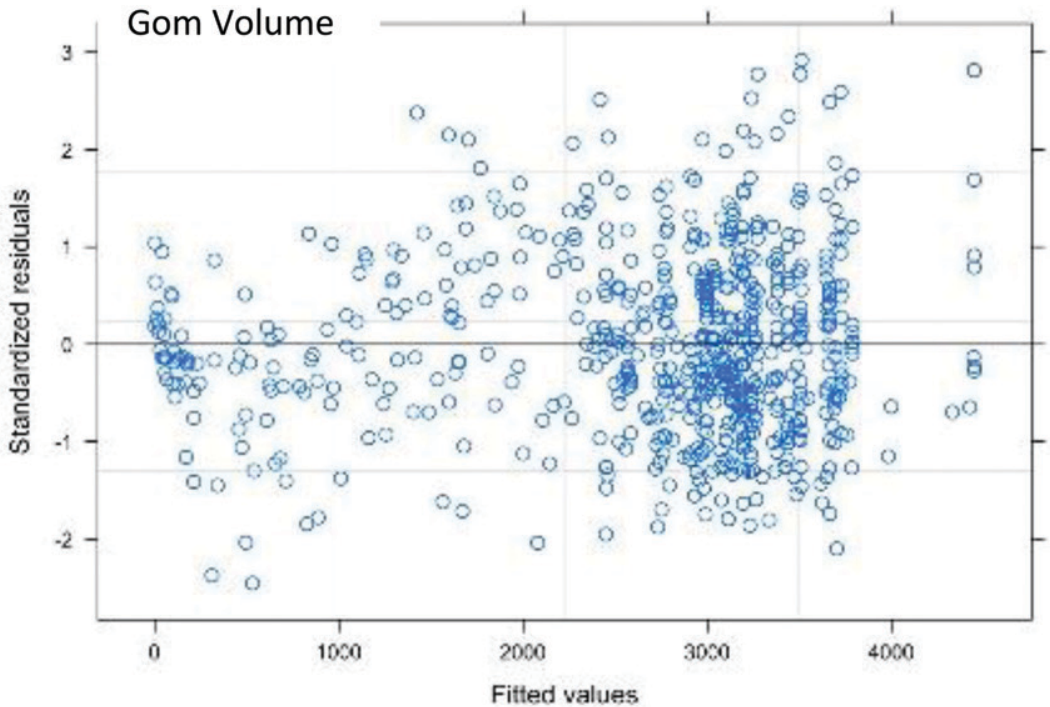

K

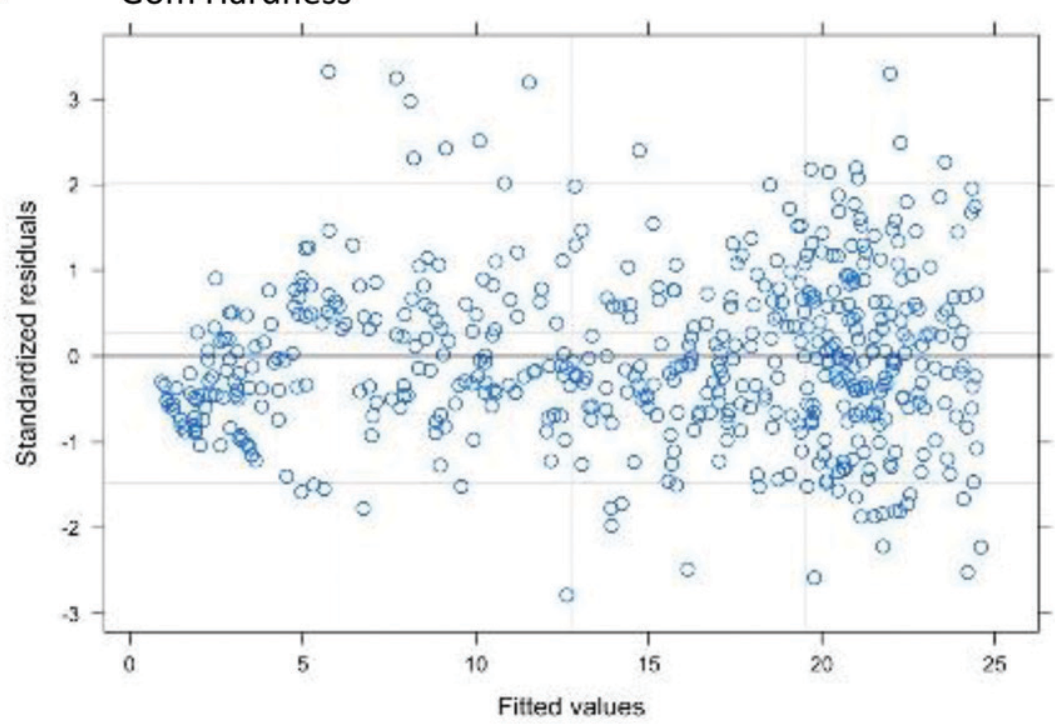

$\mathbf{L}$

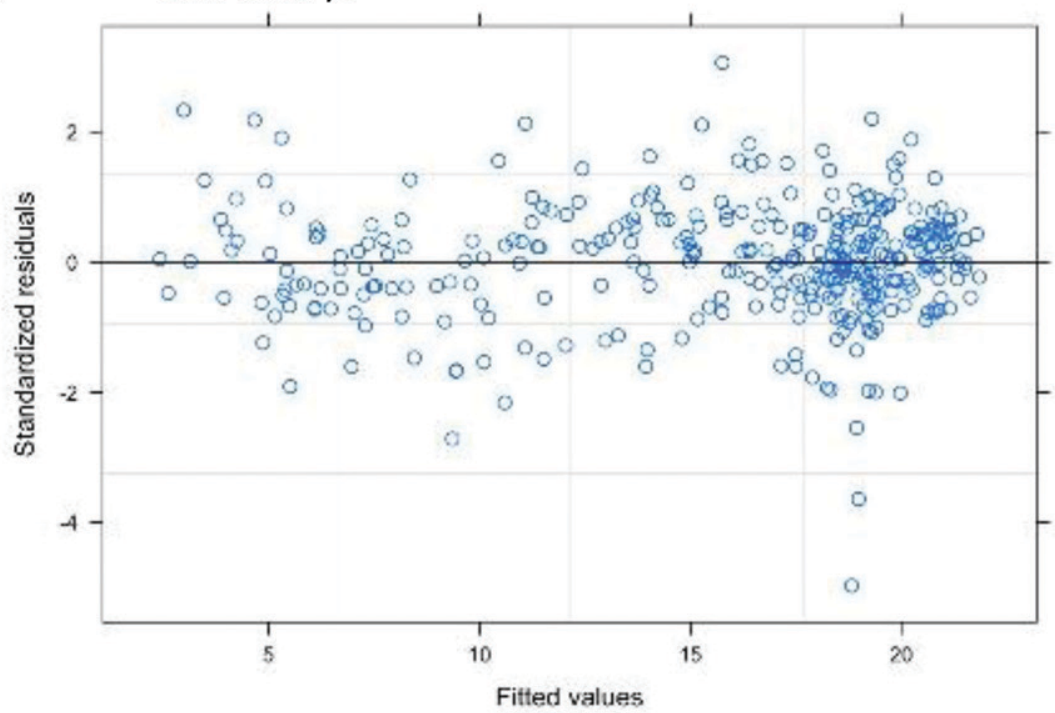

Fig. 1. (Continued) the squares of residuals, which is the difference between the observed value and the predicted value by the model. The method for a best-fitting regression curve is to find the minimum total residuals (Shaw and Laughman, 2006). With this method, the total deviation e $=$ e_year + e_site + e_year-site is set up as the full theoretical model, which is used to calculate the minimum total residuals to choose the right model.

The scatterplot of standardized residuals against predicted values should be a random pattern centered around the line of zero standard residual value. If the residuals do not follow a normal random pattern that indicates heterogeneity, the model is not a good fit. There is heterogeneity of variance in the residual distributions fitted by the asymptotic regression and Michaelis-Menten models (Fig. 1) early in the season, demonstrating that the models are too rigid for the data. They would prove unsuitable for fitting pistachio nut growth with additional data. The residuals are distributed more evenly around the center line for the zero value in the logistic and Gompertz models. A condensed cubic pattern is observed in volume and a condensed cloud is also observable in embryo length fitted by all four models late in the season. In addition to heterogeneity, this phenomenon can be explained by the pistachio's fruit growth characteristics. The fruit (pericarp and embryo) initially expands rapidly and slows later, producing a disparity in the number of late- vs. early-season observations. More data points were observed in the late, slower growth stage. In the residual scatterplots, the areas with clouds could be the result of more values being tested when the nut reached a certain size. Our results characterizing pistachio oil composition and content revealed that, late in the season, when nut size had stabilized there was active biosynthesis of fatty acids and terpenes in the kernels. These are the main compounds responsible for pistachio nutritional and sensory characteristics (Polari et al., 2019).

The nonlinear curves fitted by the model are based on repeated measurements of different experimental factors classified into effect types-fixed effects and random effects - collectively, mixed effects (Lindstrom and Bates, 1990). Random effects are used when a covariate or predictor has values sampled randomly from a population. It is assumed implicitly that additional values selected follow the same distribution as those values observed and used for the model. Fixed effects are used when the total set of predictor values of interest are measured. It is assumed implicitly that nothing is known about cases with other values of the same covariate. In our research, the predictor cultivar measured was the only one to make predictions for the six cultivars and no other cultivars need prediction, so it was the fixed effect. 'Kerman' was, until recently, the most widely planted female cultivar in California. Now, 'Lost Hills' and 
A

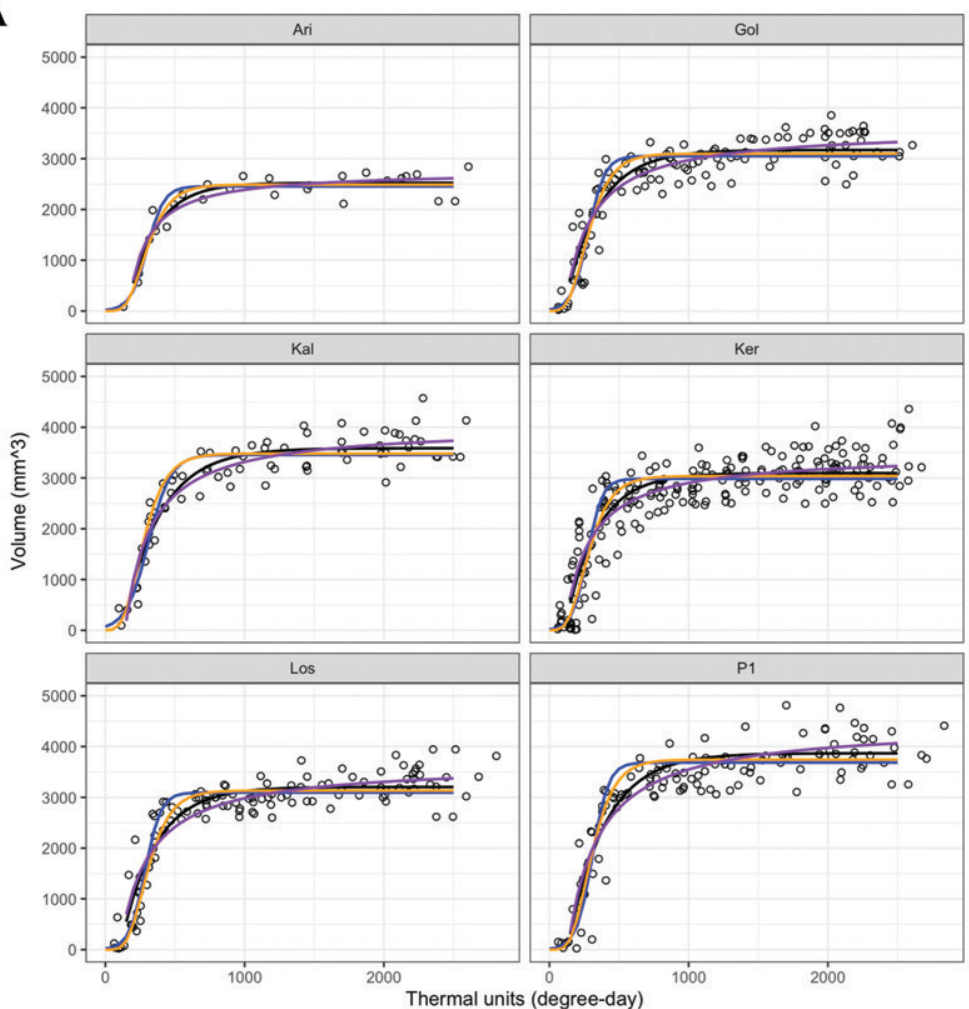

B

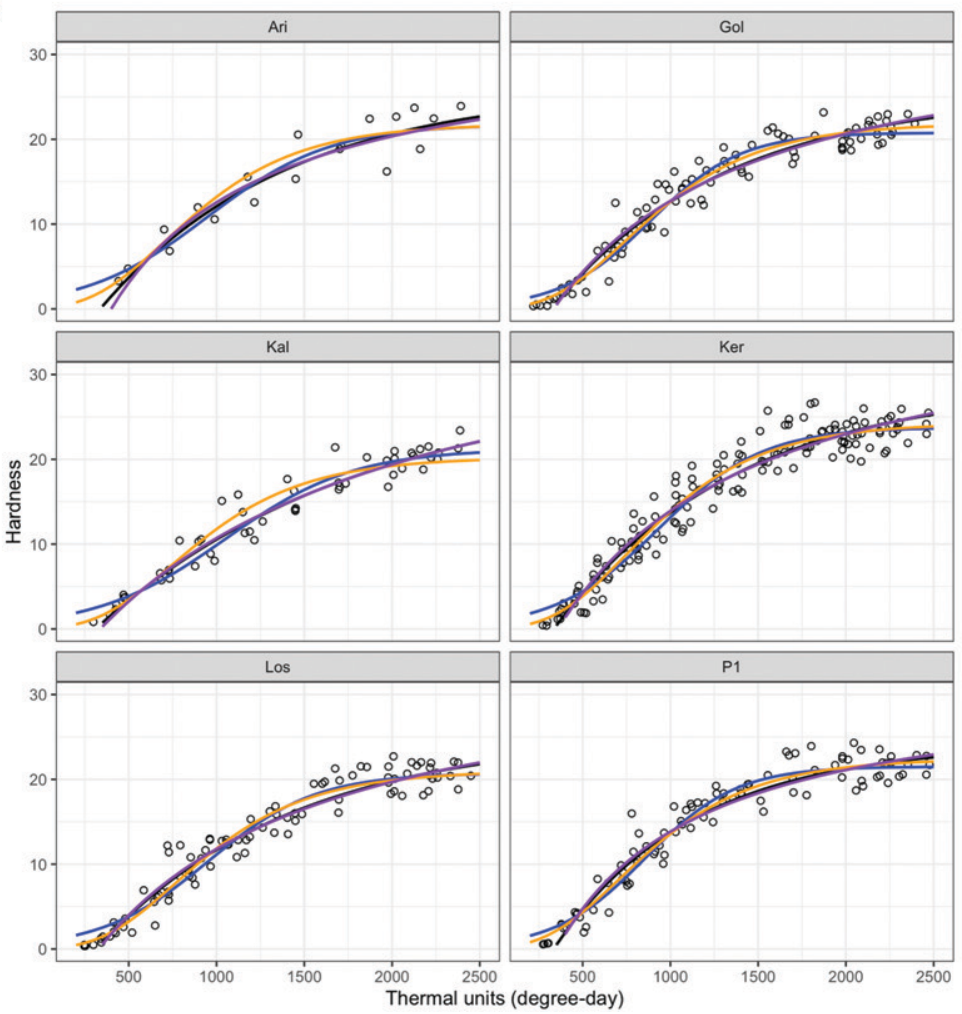

Fig. 2. (A) Nut volume expansion, (B) shell hardness increase (measured in pounds per $3 \mathrm{~mm}^{2}$ ), and (C) nut embryo length of six pistachio cultivars: Aria (Ari), Golden Hills (Gol), Kaleghouchi (Kal), Kerman (Ker), Lost Hills (Los), and Pete1 (P1). The fitted curves correspond to the asymptotic regression (black line), logistic (blue line), Gompertz (orange line), and Michaelis-Menten models (purple line) based on thermal units, with data collected in 2014, 2016, and 2017. Thermal units (degree-days) represent thermal units accumulated since flowering.

'Golden Hills' are the major cultivars being planted. 'Kalehghouchi', 'Aria', and 'Pete 1' are minor cultivars (Kallsen et al.,
2009). The cultivars in our study included the six commercial California cultivars. In this case, the cultivar for which to make predictions was in the sample used to fit the model, so it would make conditional predictions, and cultivar variance would not contribute to the uncertainty of the predictions. Year is a special case factor, because it can never be a fixed factor when the models are used in a truly forecasting manner. Therefore, year must be a random effect. Unfortunately, the number of years in the training data is small and it would not make sense to try to estimate the variance of the year effect with only 3 years of data. A possible way around this is to use the combination of site and year as a random effect that combines the variation resulting from year and site. Therefore, the full theoretical model for the year and site sources of variation is approximated by e $=$ e_year-site. The combination of site and year are the random samples of the population; therefore, if the models are well fit they can be used to predict pistachio nut growth of these six cultivars across different locations and years. This means that heat accumulation can be used as phenological time to describe nut growth if the models are fitted successfully.

After the model is fitted, applying methods to quantify the validity of fit is necessary to distinguish well- from poorly fitting models. The $R^{2}$ values in Table 3 were more than 0.86 and up to 0.95 , which is relatively high compared with $R^{2}$ applied in the reproductive organs in other temperate trees (Chuine et al., 1999). This reveals a suitability of fitness in all the nonlinear models investigated. In the three traits, the $R^{2}$ volume $\left(0.86-0.89 \mathrm{~mm}^{3}\right)$ is slightly less than the embryo length $(0.90-0.92 \mathrm{~mm})$, which was less than hardness $\left(0.94-0.95 \mathrm{lb} / 3 \mathrm{~mm}^{2}\right)$. This could be a result of the sampling frequency. As discussed earlier, the nut volume and embryo have such initial rapid growth that the residuals of the weekly or biweekly samples cannot track reliably and evenly the pace of the rapidly increasing nut volume and embryo length vs. the slowly hardening shell. A more frequent sampling schedule in the early stage, a 0 - to 500-tu range for volume, and a 750 - to 1250-tu range for embryo length in future sample collections would increase the model's precision.

To evaluate goodness of fit of the applied models, the AIC was used, which is founded on information theory and is an important method of model evaluation for parameter effect. It balances the model complexity of physiological reality with the simplicity of explainable parameter values expressed by a likelihood function that measures the suitability of fitness of a statistical model to a sample of data for given values of the unknown parameters (Burnham et al., 2011). The AIC could effectively avoid overfitting, which means producing an analysis that corresponds too precisely (complicity) to a specific data set, fails to fit additional data, and therefore has less ability to predict future events. The models with the least AIC should be selected. Compared with the other three models, the 


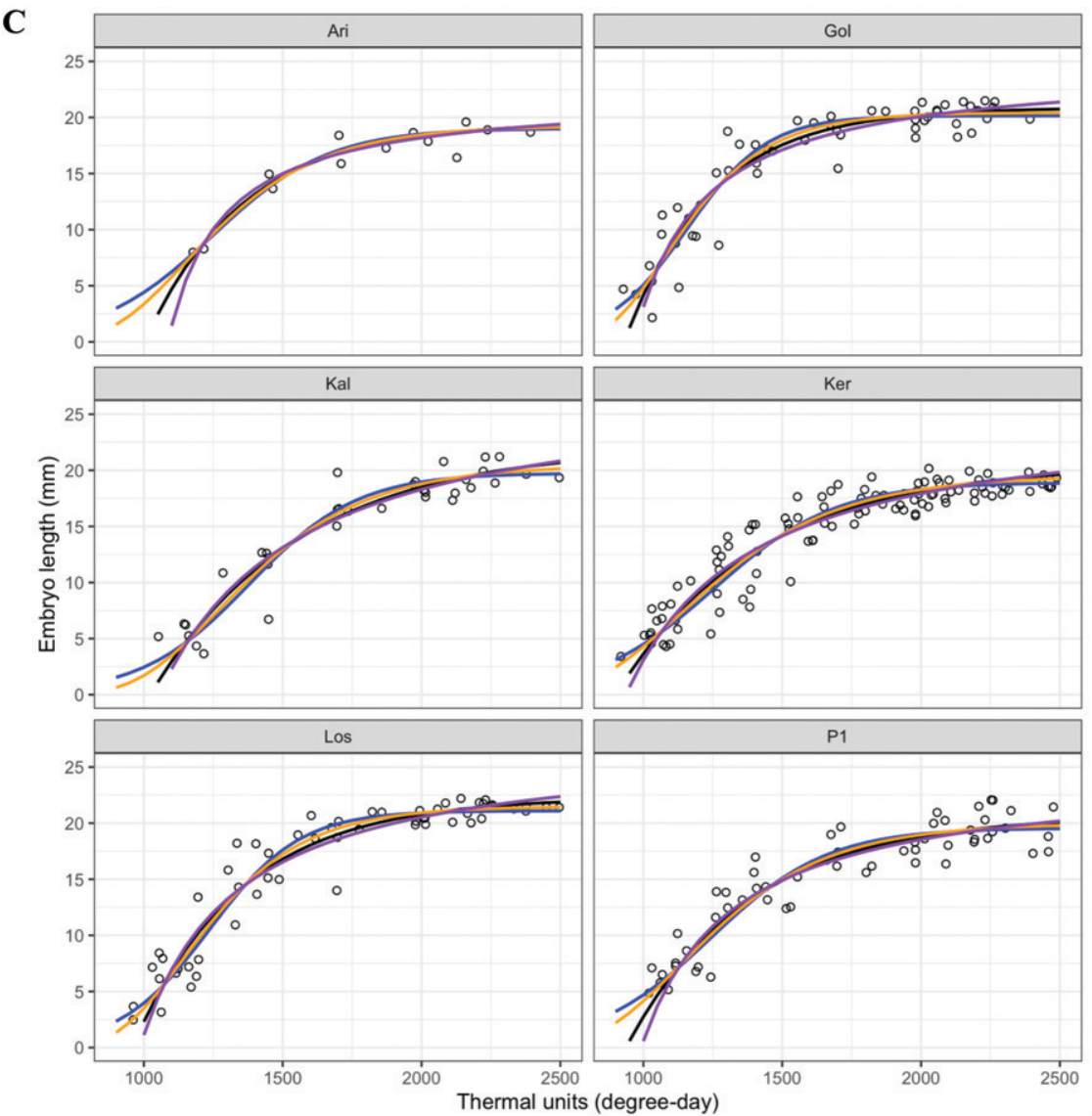

Fig. 2. (Continued)

Gompertz model had the least AIC values for all the three traits and therefore is the best model among the four fitted. The Bayesian information criteria (BIC) is another commonly used method of model evaluation, but the penalty for each parameter increases as parameter number decreases (Meade et al., 2013). Considering the four models evaluated all consist of only three parameters, the BIC was not a suitable model evaluation method and was not evaluated.

The endocarp (shell) hardness (Fig. 2B) was not an asymptotic curve like the shell and kernel. Shell hardness increased linearly, hardening completely shortly before harvest. The fully developed endocarp is high in hemicelluloses (38.5\% in mature shells) and most prominently xylan $(33.1 \%)$, around which lignin $(29.4 \%)$ provides a rigid structure (Salagado et al., 2012). Initially, the cells in this layer are flexible and lack these structural elements. Shell hardening is the result of endocarp cell lignification. During lignification, the cells produce and transport the smaller components of hemicellulose and lignin to the cell wall, where they are polymerized by laccases, peroxidases, and other chemical couplers (Li and Chapple, 2010). In Pistacia, endocarp dehiscence (shell split), the primary index of optimal harvest time, occurs before or with fruit maturation. Data thus far suggest shell dehiscence is precipitated by the physical force of kernel growth exerted on the shell suture (Polito and Pinney, 1999). Our results demonstrating shell hardness did not approach the asymptote until shell split supports the hypothesis of Polito and Pinney (1999). This suggests the correlation between shell split and hardness - specifically, the hardness curve - could be used to predict percentage of shell split, just as Polito and Pinney (1999) used the ratio of kernel to shell volume. However, hardness is easier to measure.

Nonlinear growth models are classified as two types: those with an asymptotic final size and those without it. The asymptotic final size model is suitable for describing individual plants, particularly those needing to be harvested at a certain point. In our investigation, the four models selected all belong to the asymptotic type. The main differences among the four models are as follows. First, there is no point of inflection in the curves of the asymptotic regression and Michaelis-Menten models. The curves are always concave down, and the absolute growth rate is most rapid initially and slows thereafter (Paine et al., 2012). The Michaelis-Menten equation is often used to describe enzymatic rate reactions (Schallau and Junker, 2010). The logistic and Gompertz models have inflection points, which shows the greatest growth rate, but they differ in that the inflection point of the logistic model occurs at $50 \%$ whereas the inflection of the Gompertz model occurs earlier, at $37 \%$ of the asymptote (Paine et al., 2012). In our research, the inflection point of the Gompertz model appeared earlier than in the logistic model through the season across all cultivars. This was observed obviously in the fitting of shell hardness and embryo length. The Gompertz and three-parameter logistic models fit similarly well with the pistachio nut growth data, and the residual distributions performed well in both models. Considering the significance of the fixed effect ( $P$ value) and the AIC, the Gompertz model estimated the pistachio shell and kernel growth more accurately in all three

Table 2. The impact of cultivar (fixed effect) on all parameters for evaluating the asymptotic regression, Michaelis-Menten, three-parameter logistic, and

Gompertz models fitted to pistachio nut growth data collected in 2014, 2016, and 2017 including volume, shell hardness, and embryo length.

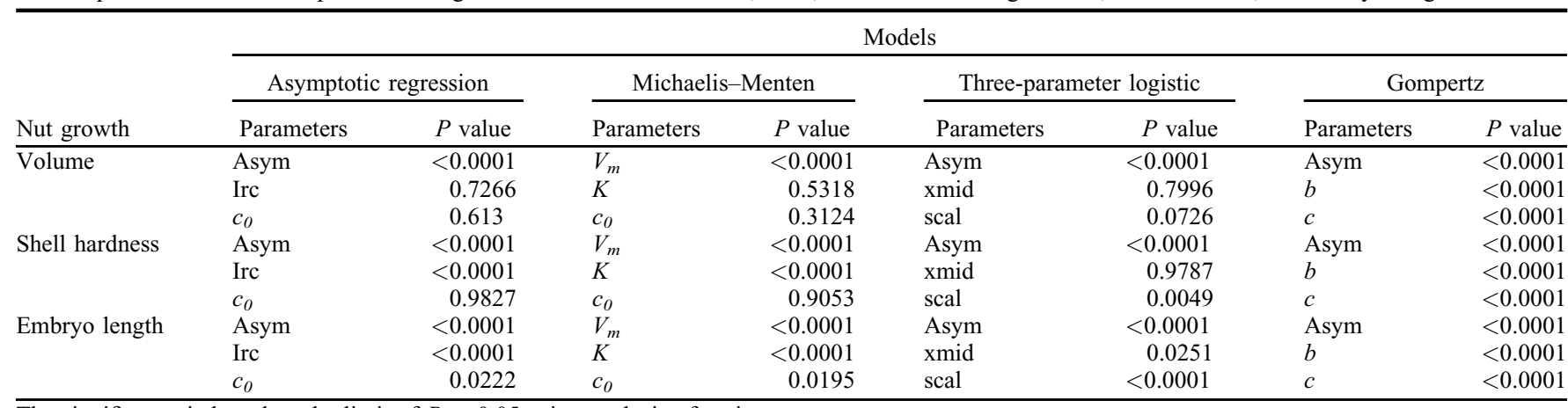

The significance is less than the limit of $P \leq 0.05$ using analysis of variance.

Asym $=$ asymptote; Irc $=$ modulates the change in slope; $c_{0}=$ offset value of $\mathrm{x} ; V_{m}=$ asymptote; $\mathrm{K}=$ distance between the value of $\mathrm{x}$ where $\mathrm{y}$ is half of $V_{m}$ and the offset; $\mathrm{xmid}=$ total thermal units; $\mathrm{scal}=$ modulates the steepness of the curve; $b=$ translates the curve in $\mathrm{x} ; c=$ determines the growth rate. 
Table 3. Coefficient of determination (marginal $R^{2}$ ) and Akaike's information criterion (AIC) for asymptotic regression and the MichaelisMenten, three-parameter logistic, and Gompertz models to predict nut volume, embryo length, and shell hardness based on data collected in 2014, 2016, and 2017 at multiple sites in California.

\begin{tabular}{llcl}
\hline Variable & \multicolumn{1}{c}{ Model } & $R^{2}$ & AIC \\
\hline Volume & Asymptotic & 0.85 & 6263 \\
Volume & Logistic & 0.83 & 6254 \\
Volume & Gompertz & 0.84 & 6241 \\
Volume & Michaelis-Menten & 0.83 & 6261 \\
Embryo & Asymptotic & 0.90 & 741 \\
Embryo & Logistic & 0.90 & 701 \\
Embryo & Gompertz & 0.91 & 690 \\
Embryo & Michaelis-Menten & 0.88 & 787 \\
Shell hardness & Asymptotic & 0.94 & 1324 \\
Shell hardness & Logistic & 0.94 & 1303 \\
Shell hardness & Gompertz & 0.94 & 1242 \\
Shell hardness & Michaelis-Menten & 0.94 & 1366 \\
\hline
\end{tabular}

traits (nut growth, shell hardness, and embryo growth).

The sigmoid Gompertz model is used frequently to describe plant growth. The Gompertz, or modified Gompertz, models were used to model the impact of freezing temperatures on the reproductive organs of pome and stone fruits (Tudela and Santibáñez, 2016). They have also been used to describe fruit/kernel growth in 'Gala' apples (Stajnko et al., 2013), four papaya cultivars (Salinas et al., 2019), and maize kernel biomass accumulation (Meade et al., 2013). For most three-parameter Gompertz models, two parameters affect the curve shape, and one shifts the curve horizontally without changing its shape (Tiørve and Tiørve, 2017). The function SSgompertz in R Statistics includes three parameters: Asym represents the asymptote, $b$ is the value of the function at $x=$ 0 , and $c$ is the scale of the $x$-axis. The values of $b$ and $c$ in SSgompertz define the curve. When the three traits (nut growth, shell hardness, and embryo growth) are combined in one graph (Fig. 4), the relationship among them is clear. Figure 4, depicts the early rapid nut growth of 'Kerman' initiated at 50 tu and approached a volumetric asymptote, peaking or inflecting at $750 \mathrm{tu}$. The shell lignification measured as hardening initiated at 100 tu and continued through 2500 tu. Kernel (embryo) growth initiated at 600 tu and approached an asymptote at 2500 tu. Between 600 and 750 tu, the nut biomass increases markedly because both embryo and shell are developing. This is a critical period in pistachio nut growth as, at this juncture, the percentage of potentially filled nuts is determined. As discussed earlier, this desert tree has a unique nut growth pattern. Not all the visually fullgrown nuts at 750 tu contain a fertilized embryo (a potential kernel), and not all those that do will grow to ripen and split the shell. The precipitating reasons for this parthenocarpy, in the first case, and kernel failure in the second case, are unknown, but perhaps we can examine their relationship with heat accumulation. Using this integrated information, web applications to predict the optimal harvest time can be constructed by converting the model's mathematical formulas to predict kernel growth and shell split. The website could be customized easily for site-specific data queries and to calculate predictions based on date, locations, and cultivar.

\section{Conclusion}

Four nonlinear fixed-effect models - asymptotic regression, Michaelis-Menten, three-parameter logistic, and Gompertz - were fitted to describe the three growth stages of a pistachio fruit: combined shell and hull (endocarp + pericarp) expansion, shell (endocarp) thickening, and hardening and kernel (embryo) expansion as a function of heat units in six $P$. vera cultivars: Aria, Kerman, Lost Hills, Golden Hills, Kaleghouchi, and Pete 1. The Gompertz model best predicted pistachio nut growth at both low and high heat unit accumulations. The Gompertz function was chosen as the most suitable model through analysis of the residual distribution, $P$ value of fixed effects on parameters, $R^{2}$ value, and the AIC.

The progression of total nut growth in volume and embryo size/mass that is rapid initially and slows later influences the model's fitness, even for the most suitable model; in this case, the Gompertz model. It caused discrepancies in the sampling that resulted in heterogeneity or 'clouds' of variance in the residual distributions and lowered the $R^{2}$ value in volume. However, these can be explained and will not influence the fitness of the models.

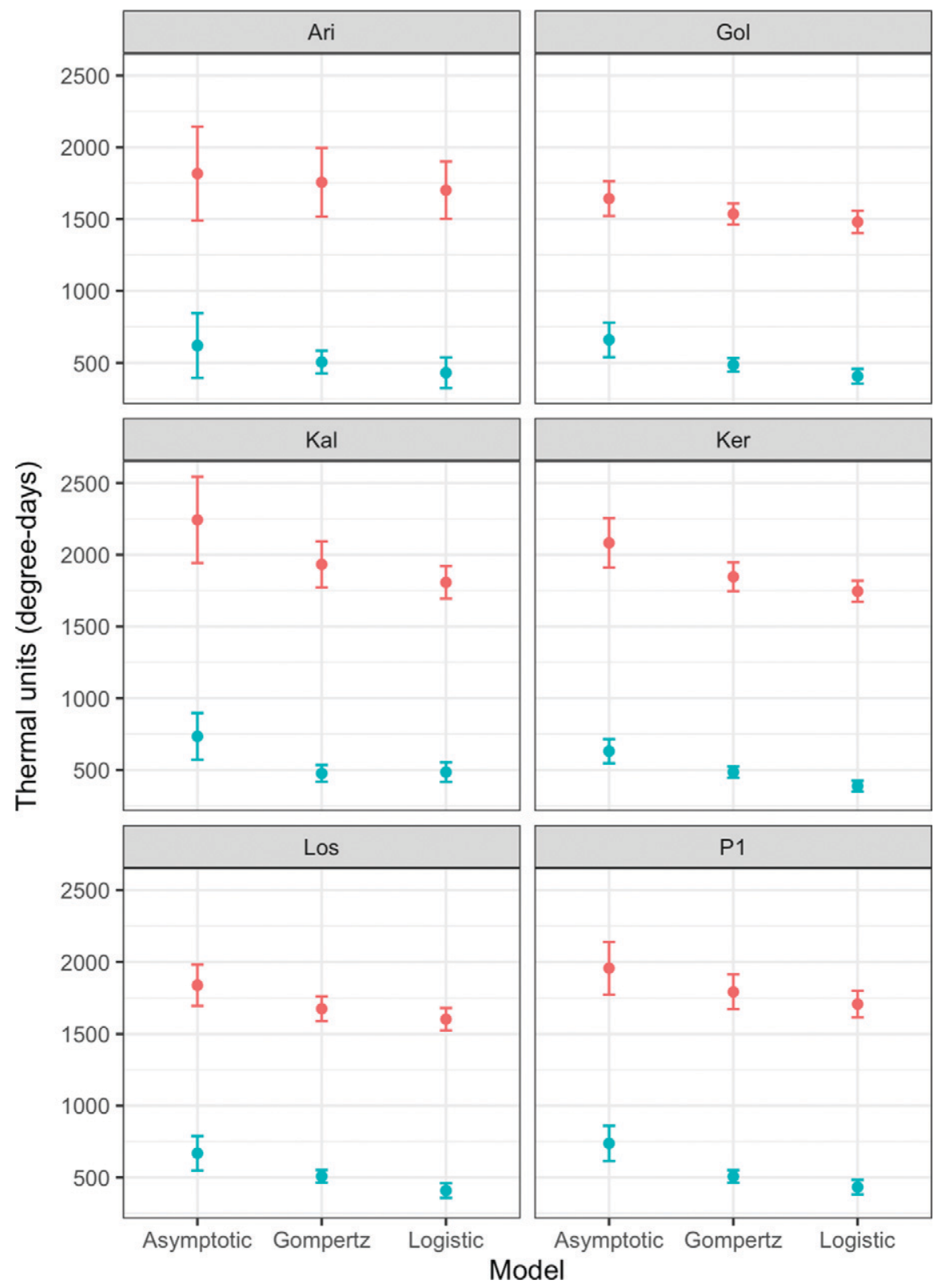

Fig. 3. Estimated thermal units necessary to reach $90 \%$ of the maximum nut volume (blue points) and embryo length (red points) as a function of model used in six pistachio cultivars: Aria (Ari), Golden Hills (Gol), Kaleghouchi (Kal), Kerman (Ker), Lost Hills (Los), and Pete1 (P1). Bars are 90\% confidence intervals. The Michaelis-Menten model was excluded because it resulted in gross overestimations. 


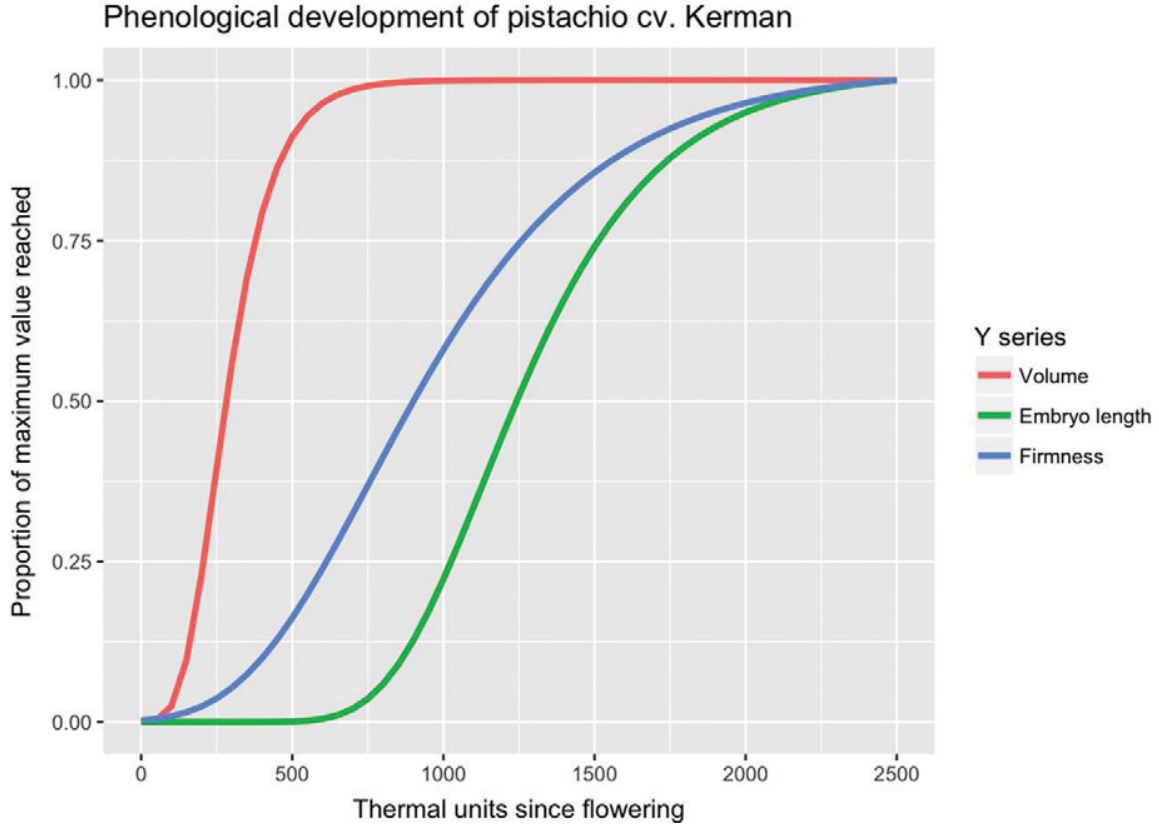

Fig. 4. The prediction of the nut growth (red, nut volume; green, embryo length; blue, shell hardness) in 'Kerman' pistachio fitted by the Gompertz model. The $y$-axis is the proportion of maximum value reached and the $x$-axis is the thermal unit accumulation, with a lower threshold of $7^{\circ} \mathrm{C}$, since bloom.

A serendipitous finding from our research is that, in building an integrated model with these three parameters (nut volume, shell hardening, and kernel growth), the integrated nut biomass accumulation, we now have the ability to assist growers by providing a web tool that can be used to access this information and use it to predict critical times for multiple orchard management practices with considerable financial impact: irrigation management, pest control and harvest timing.

\section{Literature Cited}

Benmoussa, H., E. Luedeling, M. Ghrad, J.B. Yahmed, and M.B. Mimoun. 2017. Performance of pistachio (Pistacia vera L.) in warming Mediterranean orchards. Exp. Bot. Environ. Exp. Bot. 140:76-85, doi: 10.1016/j.envexpbot.2017.05.007.

Bentley, W.J., P.B. Goodell, and R.H. Beede. 2016. Small bugs: Neurocolpus, phytocoris, calocoris, and lygus, p. 215-238. Pistachio production manual. University of California, Richmond, CA.

Burnham, K.P., D.R. Anderson, and K.P. Huyvaert. 2011. AIC model selection and multimodel inference in behavioral ecology: Some background, observation, and comparisons. Behav. Ecol. Sociobiol. 65:2335, doi: 10.1007/s00265-010-1029-6.

Chuine, I., P. Cour, and D.D. Rousseau. 1999. Selecting models to predict the timing of flowering of temperate trees: Implications for tree phenology modeling. Plant Cell Environ. 22:113, doi: 10.1046/j.1365-3040.1999.00395.x.

Chuine, I. and J. Régnière. 2017. Process-based models of phenology for plants and animals. Annu. Rev. Ecol. Evol. Syst. 48:159-182, doi: 10.1146/annurev-ecolsys-110316-022706.

Costa, L., Y. Ampatzidis, C. Rohla, N. Maness, B. Cheary, and L. Zhang. 2021. Measuring pecan nut growth utilizing machine vision and deep learning for the better understanding of the fruit growth curve. Comput. Electron. Agr. 181: 105964, doi: 10.1016/j.compag.2020.105964.
Darbyshire, R., L. Webb, I. Goodwin, and E.W.R. Barlow. 2014. Challenges in predicting climate change impacts on pome fruit phenology. Intl. J. Biometeorol. 58:1119-1133, doi: 10.1007/ s00484-013-0705-4. centa. 2003. Chilling and heat requirement of almond cultivars for flowering. Exp. Bot. Environ. Exp. Bot. 50:79-85, doi: 10.1016/S00988472(03)00002-9.

Ferguson, L., V. Polito, and C. Kallsen. 2005. The pistachio tree: Botany and physiology and factors that affect yield, p. 31-39. In: L. Ferguson (ed.). Pistachio production manual. 4th edition. Division of Agriculture and Natural Resources, University of California, Oakland, CA.

Fox, J. and S. Weisberg. 2019. An R companion to applied regression. 3rd ed. Sage Press, Thousand Oaks, CA.

Godoy, C., G. Monterubbianesi, and J. Tognetti. 2008. Analysis of highberry (Vaccinium cormixed models. Scientia Hort. 115:368-376, doi: 10.1016/J.SCIENTA.2007.10.018. 1994. Plant embryogenesis: Zygote to seed. Science 266:605-614, doi: 10.1126/ science.266.5185.605.

Goldhamer, D.A. and R.H. Beede. 2004. Regulated deficit irrigation effects on yield, nut quality and water-use efficiency of mature pistachio trees. J. Hort. Sci. 79:538-545, doi: 10.1080/ 14620316.2004.11511802.

Haviland, D.R., W.J. Bentley, J.P. Siegel, B.A. Holtz, K.M. Daane, and B.S. Higbee. 2016. Pistachio production manual, p. 197-210. University of California, Richmond, CA.

Kallsen, C.E., D.E. Parfitt, J. Maranto, and B.A Holtz. 2009. New pistachio varieties show promise for California cultivation. Calif. Agr. 63:18-23, doi: 10.3733/ca.v063n01p18.

Li, X. and C. Chapple. 2010. Understanding lignification: Challenges beyond monolignol biosynthesis. Plant Physiol. 154:449-452, doi: 10.1104/pp.110.162842.
Egea, J., E. Ortega, P. Martínez-Gómez, and F. Diymbosum L.) fruit growth with exponential

Goldberg, R.B., G. Paiva, and R. Yadegari.
Lindstrom, M.J. and D.M. Bates. 1990. Nonlinear mixed effects models for repeated measured data. Biometrics 46:673-687, doi: 10.2307/2532087.

Marra, F.P., P. Inglese, T.M. DeJong, and R.S Johnson. 2002. Thermal time requirement and harvest time forecast for pecan cultivars with different fruit development periods. Acta Hort. 592:523-529.

McMaster, G.S. and W.W. Wilhelm. 1997. Growing degree-days: One equation, two interpretations. Agr. For. Meteorol. 87:291-300, doi: 10.1016/S0168-1923(97)00027-0.

Meade, K.A., M. Cooper, and W.D. Beavis. 2013. Modeling biomass accumulation in maize kernels. Field Crops Res. 151:92-100, doi: 10.1016/j.fcr.2013.07.014.

Nakagawa, S. and H. Schielzeth. 2013. A general and simple method for obtaining $R^{2}$ from generalized linear mixed-effects models. Methods Ecol. Evol. 4:133-142, doi: 10.1111/j.2041210x.2012.00261.x.

Olsen, J.E. 2010. Light and temperature sensing and signaling in induction of bud dormancy in woody plants. Plant Mol. Biol. 73:37-47, doi: 10.1007/s11103-010-9620-9.

Paine, C.E.T., T.R. Marthews, D.R. Vogt, D. Purves, M. Rees, A. Hector, and L.A. Turnbull. 2012. How to fit nonlinear plant growth models and calculate growth rates: An update for ecologists. Methods Ecol. Evol. 3:245-256, doi: 10.1111/j.2041-210X.2011.00155.x.

Pinheiro, J., D. Bates, S. DebRoy, D. Sarkar, and R.C. Team. 2021. nlme: linear and non linear mixed effects models. R package version 3:1-152. <https://CRAN.R-project.org/ package $=$ nlme $>$.

Polari, J.J., L. Zhang, L. Ferguson, N.O. Maness, and S.C. Wang. 2019. Impact of microclimate on fatty acids and volatile terpenes in "Kerman" and "Golden Hills" pistachio (Pistacia vera). Kernels. J. Food Sci. 0:1-6, doi: 10.1111/1750-3841.14654.

Polito, V. and K. Pinney. 1999. Endocarp dehiscence in pistachio (Pistachio vera L.). Intl. J. Plant Sci. 160:827-835, doi: 10.1086/314186.

Pope, K.S., D.D. Silva, P.H. Brown, and T.M. DeJong. 2014. A biologically based approach to modeling spring phenology in temperate deciduous trees. Agr. For. Meteorol. 198-199:1523, doi: 10.1016/j.agrformet.2014.07.009.

Prusinkiewicz, P. 2004. Modeling plant growth and development. Curr. Opin. Plant Biol. 7:7983, doi: 10.1016/j.pbi.2003.11.007.

Salagado, J.M., B. Max, R. Rodriguez, N. Perez, and J.M. Dominguez. 2012. Extraction of ferulic acid from agro-industrial wastes and evaluation of bioconversion of ferulic acid to vanillin by Streptomyces setonii, p. 451-457. 1st ed. Congreso Iberoamericano Sobre Biorefinerias. CiteSeer $^{\mathrm{x}}$, Penn State College of IST. <https:// citeseerx.ist.psu.edu/viewdoc/download?doi=10.1. $1.882 .3893 \& \mathrm{rep}=\mathrm{rep} 1 \&$ type $=\mathrm{pdf}>$.

Salinas, I., J.J. Hueso, and J. Cuevas. 2019. Fruit growth model, thermal requirements and fruit size determinants in papaya cultivars grown under subtropical conditions. Scientia Hort. 246:1022-1027.

Schallau, K. and B.H. Junker. 2010. Simulating plant metabolic pathways with enzyme-kinetic models. Plant Physiol. 152:1763-1771, doi: 10.1104/pp.109.149237.

Shaw, S.R. and C.R. Laughman. 2006. A method for nonlinear least squares with structured residuals. IEEE Trans. Automat. Contr. 51:1704 1708, doi: 10.1109/TAC.2006.883036.

Sperling, O., T. Kamai, A. Tixier, A. Davidson, K. Jarvis-Shean, E. Raveh, and T.M. DeJong. 2019. Predicting bloom dates by temperature mediated kinetics of carbohydrate metabolism in 
deciduous trees. Agr. For. Meteorol. 276-277: 107643, doi: 10.1016/j.agrformet.2019.107643.

Stajnko, D., C. Rozman, M. Pavlovič, M. Beber, and P. Zadravec. 2013. Modeling of 'Gala' apple fruits diameter for improving the accuracy of early yield prediction. Scientia Hort. 160: 306-312, doi: 10.1016/j.scienta.2013.06.003.

Stanley, C.J., D.S. Tustin, G.B. Lupton, S. Mcartney, W.M. Cashmore, and H.N. De Silva. 2015. Toward understanding the role of temperature in apple fruit growth responses in three geographical regions within New Zealand. J. Hort. Sci. Biotechnol. 75:413-422, doi: 10.1080/14620316.2000.11511261.

Tiørve, K.M.C. and E. Tiørve. 2017. The use of Gompertz models in growth analyses, and new
Gompertz-model approach: An addition to the Unified-Richards family. PLoS One 12: e0178691, doi: 10.1371/journal.pone.0178691.

Tudela, V. and F. Santibáñez. 2016. Modeling impact of freezing temperatures on productive organs of deciduous fruit trees. Agr. For. Meteorol. 226-227:28-36, doi: 10.1016/ j.agrformet.2016.05.002.

Wilson, L.T. and W.W. Barnett. 1983. Degreedays: An aid in crop and pest management. Calif. Agr. 37:4-7, doi: 10.3733/ca.v037n01p4.

Yin, X., M.J. Kropff, G. McLaren, and R.M. Visperas. 1995. A nonlinear model for crop development as a function of temperature. Agr. For. Meteorol. 77:1-16, doi: 10.1016/ 0168-1923(95)02236-Q.
Zapata, D., M. Salazar, B. Chaves, M. Keller, and G. Hoogenboom. 2015. Estimation of the base temperature and growth phase duration in terms of thermal time for four grapevine cultivars. Intl. J. Biometeorol. 59:1771-1781, doi: 10.1007/s00484-015-0985-y.

Zavalloni, C., J.A. Andresen, and J.A. Flore. 2006. Phenological models of flower bud stages and fruit growth of 'Montmorency' sour cherry based on growing degree-day accumulation. J. Amer. Soc. Hort. Sci. 131:601-607, doi: 10.21273/JASHS.131.5.601.

Zhang, J., T. Ranford, and C. Taylor. 2015. Heat model for pistachio bloom and harvest. Scientia Hort. 186:47-53, doi: 10.21273/ HORTSCI11775-17. 